\title{
Securing the Eldenty Body: Dementia, Surveillance, and the Politics of "Aging in Place"**
}

\author{
Alison Marie Kenner 1
}

\begin{abstract}
Aging in place, the option to grow old in one's home instead of institutional healthcare facilities, is predicated on the development of technologies and resources that network patients, caregivers, medical personnel, and third party interlocutors. Monitoring systems and other information technologies are broadly considered to be the most promising means to establish these connections, and home care technologies for elderly people with dementia comprise one of the fastest growing areas of commercial development. Grounded in the political economy of aging and understood as surveillance, monitoring technologies for the elderly highlight sociopolitical responses to aging and dementia and raise critical questions about caregiving, quality of life, and the way technological design engages with everyday rights. This paper will analyze surveillance technologies for the elderly with attention to issues of power and inequality, and how these dynamics may or may not be considered in technological design for the oldest populations.
\end{abstract}

\section{Introduction}

Aging has been constructed as a problem in the US because rapidly expanding elderly populations now pose a great threat to US healthcare and social service systems. This threat is reflected in public policy, healthcare regimes, scientific research, and market innovations that treat elderly bodies as beset by decline, deterioration, and age-related diseases that require intervention (Estes, 1993: 292; Joyce and Mamo, 2006: 99). Aging in Place, the option to grow old in one's home instead of institutional healthcare facilities, is increasingly recognized as a preferred strategy for supporting the elderly who may be less independent than they were previously. If caregiving resources can be brought into the home, the burdens of elderly care could be greatly reduced. Yet the ability to effectively provide healthcare in the home is predicated on the development of technologies and resources that network patients, caregivers, medical personnel, and third party

\footnotetext{
* I am grateful to Nancy Campbell, Jonathan Cluck, Camar Diaz-Torres, Kim Fortun, David Hess, Dean Nieusma, and Grant Jun Otsuki for reading and providing feedback on various versions of this paper. I would also like to thank Torin Monahan, Jill Fisher, and the anonymous reviewers for very thorough and insightful comments. This paper was inspired by conversations with Christine E. Kenner as well as many others who have shared their thoughts on dementia care with me.

${ }^{1}$ Department of Science and Technology Studies, Rensselaer Polytechnic Institute, New York. mailto:kennea2@rpi.edu
} 
interlocutors (Harbert, 2006: 75).

Monitoring systems and other information and communication technologies (ICT) are broadly considered to be the most promising means to establish these connections, and home care technologies for elderly people with dementia comprise one of the fastest growing areas of commercial development. Monitoring systems are attractive because they have the potential to reduce the costs and burdens of caregiving while increasing safety and autonomy in old age. In the case of dementia, monitoring technologies relieve caregivers from the need to keep a vigilant eye on the elder's movements. These technologies may allow the elderly to age in place without direct, 24-hour supervision by formal or informal caregivers. Technologies are also being tested for their ability to detect the onset or progression of dementia through movement patterns, a diagnostic application that fits with broader trends to make healthcare more efficient and cost effective using ICTs.

Despite the tremendous potential for surveillance technologies to assist and improve the quality of life for those with dementia, most care systems currently under development emphasize managing risk of injury or death posed by the disease (Orpwood et al., 2007: 103). Many products are security spin-offs ranging from door alarms and childproof locks, to full-scale monitoring systems that use infrared sensors, webcams, and radiofrequency identification (RFID), some of which link to the Internet for the use of family members or caregivers. Such shifts in elderly care translate daily behaviors into data about the body that may then be analyzed, categorized, and regulated at a distance from the social and material context at hand (Lyon, 2003; Monahan and Wall, 2007).

Monitoring systems for dementia care call to mind similar products used for children or prisoners on house arrest (Katz, 2006; Monahan, 2006). Like these groups, elderly citizens, and those with dementia in particular, are often in a position that makes them vulnerable. Healthy or otherwise, older populations typically depend on support and resources from the social service system and their families; they may have substantially less control over decisions that affect their lives than they previously did (King, 2006: 5758). The elderly are also much more likely to be the victims of abuse, mistreatment, neglect, and violence (Laws, 1995: 113). How might surveillance technologies for the elderly reflect ageism in society? For all the benevolent and lifesaving scenarios one may come up with, considering the position of many elderly citizens, there might be an equal number of negative and oppressive situations that monitoring technologies enable.

The crisis posed by an aging population has made securing the elderly body a top priority for US policymakers, law enforcement agencies, healthcare professionals, caregivers, families, and the elderly. Understood as surveillance, monitoring technologies for the elderly highlight sociopolitical responses to aging and dementia and raise critical questions about caregiving, quality of life, and the way technological design engages with everyday individual rights. Our responses to dementia among rapidly expanding elderly populations are complex, layered, and controversial, and even more so when examining the various sites where dementia has become a social, medical, economic, and political problem. Monitoring technologies used to evaluate elderly behaviors, security systems designed for dementia care, and the need for support from law enforcement agencies all reflect current challenges and transitions in elderly care. Following Carroll Estes’ (1993) 
call for social research and policy that shifts the focus away from cost and efficiency and towards empowerment and equity, this paper will analyze surveillance technologies for the elderly with attention to issues of power and inequality, along with inquiry into the design of surveillance technologies for the oldest populations.

\section{The Political Ec onomy of Aging}

The term "dementia" refers to a collection of disorders that cause irreversible and progressive cognitive impairment affecting memory, communication, judgment, and visual mapping in ways that interfere with everyday life. Alzheimer's Disease ${ }^{2}$ (AD) is the most common dementia, accounting for up to $70 \%$ of all cases, and is widely known as a disease that develops in the elderly. But AD has not always occupied its current place in public culture, medical research, and national health policy. Historically, “Alzheimer's" referred to presenile dementia, or cases where people under the age of 60 developed dementia. It wasn't until the late 1970s that research showed the hallmark signs of AD in senile dementia as well (Gubrium, 1986: 5). With recognition that neurodegeneracy of the Alzheimer's type looked the same at any age came the revelation that senile dementia was not a normal part of aging, but rather a pathological condition. This immediately led to research on its prevalence and impact, creating public visibility that has grown steadily over the last 25 years.

Undoubtedly, this visibility stems from the way AD-dementia has been framed as a public health issue by organizations such as the Alzheimer's Association and the National Institute on Aging. In a recent report, "Alzheimer's Disease Facts and Figures," the Alzheimer's Association estimated that the number of Americans living with AD had risen to 5.1 million, a number that is expected to reach 16 million by 2050 (Alzheimer's Association, 2007: 5). Behind this prediction are studies showing that $42 \%$ of people 85 and older, one of the fastest growing age groups in the country, have some form of dementia: "Every 72 seconds, someone in America develops Alzheimer's disease; by mid-century, someone will develop Alzheimer's every 33 seconds" (Alzheimer's Association, 2007: 5). This turning point in dementia classification and awareness is situated within the political economy of aging in the US, where "social policies pertaining to retirement income, health, and social service benefits and entitlements are seen as products of economic, political, and sociocultural processes and forces that interact in any given sociohistorical period," effectively shaping the conditions of old age (Estes \& Assoc., 2001: 40).

Written in 1979, Estes' book, The Aging Enterprise, describes how the lives of elderly Americans are constructed by policies and attitudes that problematize aging and how our responses to the needs of the elderly are shaped by broader social and political structures such as employment, retirement, medical industries, and family life. Estes connects the

\footnotetext{
2 In research and literature, it is common for the term “Alzheimer's disease” (AD) to mean Alzheimer's disease and related dementias, including Multi-infarct dementia, Pick’s disease, Binswanger’s disease, Parkinson's disease, and mixed dementia, which have similar symptoms in and impacts on the patients. In this paper the term dementia refers to this group of neurodegenerative disorders (Alzheimer's Association, 2007: 2).
} 
aging enterprise to legislation such as the US Older Americans Act (1965) and Medicare, landmark changes in policy that target elderly needs. Over the last few decades, deregulation has had the effect of shredding social safety nets - the result has been privatization and fragmentation of services, the growth of for-profit care, and industry consolidation throughout the healthcare system, processes largely supported by government subsidies (Estes, 2001: 51). These social policies transformed elderly needs into commodities, creating an economic market to be served by "the aging enterprise." The commodification of aging has converted social rights into consumables that the individual becomes responsible for obtaining (Twine, 1994; Estes, 2001: 52). Of course the commodification of elderly needs would not have been possible without the biomedicalization of aging: "the social construction of aging as a medical problem - that is, thinking of aging itself primarily as a disease and/or problem as defined by medical practitioners - and, second, the praxis (or practice) of aging as a medical problem and the behaviors and policies growing out of thinking of aging in this way” (Estes, 2001: 46).

Biomedicalization has developed in conjunction with the aging enterprise, the system that serves the aging population by isolating elderly needs from those of other age groups and treating those needs as commodities (Estes, 1993: 292). Under the biomedical model, aging is treated as pathological and is managed through clinical treatments established by medical professionals; it shapes the direction of research, medical education, public culture, and social policy (Estes, 2001: 46). This approach to aging has rendered invisible the social, political, and economic forces that condition old age and create problems for elderly populations.

The link between the commodification and biomedicalization of aging can be observed in the technologies, institutions, and knowledges produced and used in care settings. Characterized by technoscientific innovations that expand healthcare regimes through the commodification of health, the creation of risk groups, and the deployment of surveillance technologies across organizations,

Biomedicalization is reciprocally constituted and manifest through five major interactive processes: (1) the politico-economic constitution of the Biomedical TechnoService Complex, Inc.; (2) the focus on health itself and elaboration of risk and surveillance biomedicines; (3) the increasingly technoscientific nature of the practices and innovations of biomedicine; (4) transformations of biomedical knowledge production, information management, distribution and consumption; and (5) transformations of bodies to include new properties and the production of new individual and collective technoscientific identities. (Clarke et al., 2003: 163)

Biomedical technologies are not only changing how healthcare is practiced but also its jurisdiction. The result has been a shift in attitude and approach to aging, and to dementia in particular (the nosological shift in $\mathrm{AD}$ is one example). One of the most prevalent mechanisms of biomedicalization is that, by creating risk factors that can be identified through observation-thus motivating and justifying surveillance practices-these regimes make it impossible for one not to be considered at risk (Clarke et al., 2003: 172). Risk assessment tools and health knowledges may normalize behavioral patterns, "not in the sense that they produce bodies or objects that conform to a particular type, but more 
that they create standard models against which objects and actions are judged" (Clarke et al., 2003: 172). This is not to say that the risk does not exist, but that the techniques, experts, and technologies that elaborate upon and evaluate risk simultaneously justify increased use of surveillance. Caught in controversies over what is normal, pathological, and successful aging, older Americans already diagnosed with dementia have become surveillance targets. As David Lyon points out, surveillance systems may be proliferating because of "the increasing number of perceived and actual risks and the desire more completely to manage populations" (2003: 20). Targeting the needs of those seeking to age in place becomes important, not only for the medical-industrial complex that depends on an aging market, but also because the commodification and biomedicalization of aging fails to serve the expanding elderly population.

In the last 25-years, social programs for older Americans have not kept up with the expanding elderly population or the systemic changes that have transformed their needs and given rise to new ones. Although it would be a mistake to equate the problems faced by the elderly with those of dementia sufferers, there is still an important connection between the two-dementia is a disease that develops in old age, and it has overwhelmingly been framed as an elderly problem:

Phenomena associated with chronological aging and intrinsic biological conditions may be said to be objectively real, regardless of how they are perceived. The key point is, however, that social action is indivisible from the socially constructed ideas that define and provide images of the phenomena of old age and ageing-whether or not these images are empirically demonstrated. (Estes, 1993: 292)

The case of dementia is significant because it overlaps and connects with many other issues that people face as they age-living alone, traveling safely, diminished income, increased dependence, expensive medical care, and more general changes in cognitive, behavioral, and physical functioning. Invisibility and marginalization are also prevalent among the elderly, who may not fit idealized norms of productive citizenship after childbearing and retirement years (Laws, 1995: 115; King, 2006: 54).

Those afflicted by dementia are not the only ones affected. The political economy of aging reflects shifting family structures, declining wages, and fewer voluntary and nonprofit resources; changes produced by the sociocultural, economic, and political forces of the postwar era have both created and reinforced institutionalized patterns of power and inequality (Estes, 1993: 294; Estes \& Assoc., 2001: 40; King, 2006). These trends have generated tremendous challenges for both formal and informal caregivers. In fact, the effects of neoliberalism on elderly caregiving have dispersed hardships across the spectrum, weighing on families, employers, social service providers, and even law enforcement agencies. According to the Alzheimer's Association report, the national cost of dementia has risen to nearly $\$ 150$ billion annually, including Medicare, Medicaid, and indirect costs to businesses employing caregivers (2007). Dementia care also impacts upon the domestic and informal labor sectors. With 70\% of those afflicted living at home, as many as 10 million Americans care for someone with dementia; unpaid labor was valued in 2005 at $\$ 83$ billion (Alzheimer's Association, 2007: 13). These caregivers often provide care for more than forty hours a week and report higher levels of emotional stress, 
miss more days of work, and are less able to maintain their own health than other caregivers (Alzheimer’s Association, 2007: 17).

The commodification and biomedicalization of aging has also widened the gap between the haves and have-nots, stratifying care and services according to social and economic privilege (Clarke et al., 2003). The privatized and medicalized care system in the US places the financial burden of aging on individuals, and these effects are distributed in accord with the interlockings of oppression-gendered, racialized, and class-based structures that create hierarchical social positions. The political economy of aging is experienced differently by women, people of color, and low-income families who may have less privilege and resources on which to draw (Laws, 1995; Estes \& Assoc., 2001: 13). Discussed in a social, political, and economic frame, dementia is an extremely costly medical condition draining social service and caregiving resources; its effects will undoubtedly be differentially experienced based on social position. With projections of rising prevalence, dementia has been described as one of the most urgent public health issues of the $21^{\text {st }}$ century (Sloane et al., 2002).

\section{Sec uring the Edenty Body}

The structural inequalities and power asymmetries reproduced by the commodification and biomedicalization of aging become quite visible when elderly care becomes an elderly crisis. This is particularly salient when considering the case of Lillian Fletcher, an 82-year old woman diagnosed with dementia and schizophrenia. After an anonymous call to the Department of Aging reported that Fletcher was alone and in need of assistance, Chicago Police visited her home to conduct a well-being check (Mitchell, 2007). When the police came to the door, Fletcher refused to allow them in; they entered anyways. Fletcher then grabbed a hammer, which prompted the police to use a Taser to subdue her. Tracy Taylor, granddaughter and one of Fletcher's caregivers, said that her grandmother is often confused, sometimes belligerent, but probably did not know what was going on. Describing her grandmother as 5'1" and 160 lbs, Taylor reacted: "I just don't think they should be Tasing 82-year-old women. That's ridiculous... There has to be another way to stop her -- use your stick and block the hammer" (Mitchell, 2007). In this case the reason for the well-being check was not particularly clear. Was Fletcher not to be left alone? Was she or were others in danger? News reports seem to indicate that there was a lapse in Fletcher's caregiving, which led to state intervention (Mitchell, 2007). This incident points to the gaps and schisms in societal responses to elderly welfare. When do older Americans need assistance, what forms should intervention take, and what are the best ways to ensure the wellbeing of the elderly?

US literatures on aging are marked by fearful discourses that highlight the dangers of old age and urge families to take precautions to reduce risks. This discourse is augmented tenfold when discussing elderly people with dementia, a group that has been referred to as “a social policy time bomb" (Silverstein et al., 2002: 4). If elderly people with dementia are going to be living at home, alone or with periodic visits from caregivers, will they be safe, and who will be responsible for ensuring their wellbeing? Fletcher's visit from Chicago Police calls to mind warnings about dementia as a social policy time bomb. Will 
aging in place with dementia overburden social services and lead to unwise and inhumane actions as seen above? Lillian Fletcher's case may not be that unique, especially considering the frequency with which law enforcement agencies are called on in crisis situations involving elderly people with dementia (Silverstein et al., 2002).

One of the most common situations is critical wandering, estimated to be as high as 125,000 a year in the US (Silverstein et al., 2002: 34). For elderly people with dementia, wandering $^{3}$ is a risky behavior because of the potential for a person to become lost, confused, and forget where they are. It is frequently reported as the cause of hospital visits, physical injury, emotional strain, and death, and is a principle factor in decisions to institutionalize the elderly (Silverstein et al., 2002). In Dementia and Wandering Behavior, Silverstein, Flaherty, and Tobin argue that, out of all dementia care issues, wandering warrants the most attention and must become a top priority in order to effectively manage care: "Elder care providers need to address the wandering process before it creates the kinds of crises which an overburdened elder service system is not currently equipped to resolve in the safest, wisest or most humane way" (Silverstein et al., 2002: 7).

Already, wandering has generated responses from unlikely state actors. In Florida, for example, the Sarasota Police Department recently purchased 125 electronic bracelets that emit a tracking signal for Project Lifesaver, ${ }^{4}$ a program established to help find those with dementia who wander off and become lost. With 50,000 elderly residents living with dementia, Sarasota law enforcement officers are frequently called in for search and rescue support. The electronic bracelet (which costs $\$ 275$ plus a $\$ 7$ monthly fee for batteries) dramatically improves rescue efforts for missing persons, dropping recovery time averages to just 30-minutes (Gray, 2007). Although the first few purchases have been made for nursing home residents, the greatest use will likely be in private homes. However, as one geriatric specialist warned, the bracelets cannot be used simply as a substitute for home care: "You just cannot think [elders with dementia] can be left at home and we'll know where they are and they will be all right" (Gray, 2007). This is just one of many examples where local law enforcement agencies have become more active in efforts to address dementia wandering (Silverstein et al., 2002; Project Lifesaver, 2007).

Other state agents are also calling for technologies to secure the elderly. Recently an Australian coroner recommended the use of CCTV in nursing homes as increased safety measures, specifically for those with dementia (ABC News, 2007). As David Lyon has pointed out, surveillance technologies are "actively sought and developed because they answer to particular political-economic pressures” (2001: 26). Admittedly, news reports of elderly people who are missing or lost can be found almost daily. ${ }^{5}$ The use of RFID bracelets seems to be an effective solution to a critical problem affecting the elderly, caregivers, and law enforcement. What must be examined is how the political economy of

\footnotetext{
${ }^{3}$ Wandering is defined as "movement by a person with dementia, whether aimless or purposeful, on foot or by other means, which occurs when certain cognitive losses and environmental circumstances intersect, causing that person to become lost in an unsupervised and potentially unsafe setting." (Silverstein et al., 2002: 35)

4 http://www.sarasotagov.com/InsideCityGovernment/Content/Police/Lifesaver.htm

${ }^{5}$ I base this statement on my daily, ongoing survey of the elderly and dementia in the media.
} 
aging creates and conditions a technoscientific response, surveillance technologies, to a previously marginalized issue-the invisibility and isolation experienced in old age. The trick is figuring out how to look past surveillance solutions and to analyze these technologies as a mechanism of social sorting (Lyon, 2001).

\section{Dementia Care, Fully Controlled}

What is significant about current social and political responses to aging is the construction of rapidly expanding risk groups among the elderly - and those with dementia are just one of many such groups. To combat this "social policy time bomb," emphasis has been placed on "early onset" and catching the disease before it develops into its more debilitating stages. This is a precautionary move where interventions in elderly peoples' activities, their living environments, or caregiving can be made before the symptoms of dementia create crisis situations (Silverstein et al., 2001; Alzheimer's Association, 2006). Detecting the onset of dementia can be quite difficult given the similarities with "normal" cognitive and behavioral changes that individuals experience as they age. This is why surveillance technologies are said to hold such promise: they have the potential to both detect pathological behavior patterns (such as abnormal sleep cycles, pacing, and confusion) and to keep at-risk elderly populations secure.

In the late 1980s, the desire to establish a "gold standard" for evaluating wandering led researchers to develop monitoring technologies that could track ambulation in the elderly (Algase et al., 2003: 86). Fifteen years later, biomechanical activity devices are still used to study wandering, and these products continue to be considered the most accurate and cost efficient means for measuring movement patterns in elderly people with dementia. A recent study, for example, looked at how well four biomechanical monitoring devices indexed mobility according to the wandering typology developed by Martino-Saltzman et al., "conceived as time ambulating in a random, lapping, or pacing pattern" (MartinoSaltzman et al. 1991: 667-668). These technologies are employed to track and code specific behavioral patterns in order to formulate better classification systems or to validate existing ones (such as Martino-Saltzman's). The study was conducted in nursing homes and assisted living facilities with the intention of evaluating whether monitoring systems could contribute to understandings of dementia behavior. Central to this study was an assessment of the clinical acceptability of the biomechanical devices from the perspective of nursing staff (Algase et al., 2003: 86). The devices examined included the "StepWatch," "Actillume," "TriTrac-R3D," and "Step Sensor," all of which varied in mechanical type, size, placement, and use of ICTs (2003: 86). Since all of the devices had to be worn by dementia residents, the comfortability, safety, ease of cleaning and maintenance, and appearance all played a role in how well these monitoring products measured movement patterns. The residents' interaction with these devices usually skewed data (Algase et al., 2003). Two of the four devices, the StepWatch ${ }^{6}$ and Actillume, were both about the size of a large diver's watch and were attached to participants' left legs. The TriTrac-R3D was the size of a small transistor radio and was held in a pouch on participants' hips. The Step Sensor - the one found most acceptable to nursing staff based on the above criteria-was a step counting device placed in the heel of

\footnotetext{
6 http://www.cymatech.com/index.html
} 
participants' shoes; the StepWatch was also a step counting device. Both the TriTrac-R3D and Actillume were accelerometers-devices that measure motion. With the exception of the Actillume, all the devices either interfaced with a computer or had external displays; data were also collected using a MacSema BestWand ${ }^{7}$, a bar code reader that could be programmed to extract data from each device using a standardized coding system (Algase, 2003: 88). The monitoring products measured ambulatory dimensions by episode pattern and duration, which were then evaluated according to the movement typology developed by Martino-Saltzman et al. (1991: 667). Types included random, lapping, pacing, and direct patterns:

$[\mathrm{R}]$ andom is haphazard locomotion having many hesitations and direction changes; lapping is circuitous locomotion following a repetitive route or path; pacing is back-and-forth locomotion between two points; and direct is an undiverted path between a start point and a destination. (Algase, 2003: 88)

This algorithm exemplifies the translation of motor behavior-steps-into somatic data (Monahan and Wall, 2007). This data can be uploaded to information networks where it may be analyzed and later used to justify intervention, such as access restriction or the use of lock and departure alert products, like the WanderGuard ${ }^{8}$, commonly found in nursing homes. Although the study by Algase et al. was largely concerned with evaluating monitoring devices and wandering typology for dementia research, their conclusion suggests that the StepWatch could be a useful tool for determining mobility patterns that affect health and safety, and "as a means to evaluate the effectiveness of interventions aimed to reduce or redistribute wandering behavior" (2003: 91).

Other studies on dementia behaviors use sensor devices positioned within the residential space instead of on the body. This was the approach taken by Chan, Campo, Laval, and Esteve (2002), whose goal was to develop monitoring systems that track the ambulation and activities of nursing home residents with dementia. The monitoring system used for this study was composed of eight infrared sensors positioned around the patient's roomincluding the bed, washroom, and door-which were then linked to a computer that automatically collected and processed somatic data within a spatial-temporal frame. The activities measured included going to bed, getting out of bed, visiting the washroom, leaving the room, and wandering (Chan et al., 2002). ${ }^{9}$ In this institutional setting, nursing records include data only from patients and staff entering or leaving rooms. Even then, not every incident is reported and records often vary between staff members (Chan et al., 2002). The infrared sensor system, on the other hand, is able to consistently and continuously monitor patient movement and is intended to supplement caregiving staff records. In light of this, "The system could be very useful when surveying disorders in the demented with motor disorders...[and] could suffice to detect typical changes in the

\footnotetext{
7 http://www.macsema.com/bestwandI.htm

8 http://www.seniortechnologies.com/products/wanderguard/default.asp?type=residential

${ }^{9}$ In this study, the caregiver's whereabouts were also tracked upon entering the area under surveillance, although data did not appear to hold significance beyond the technical logistics of tabulating movement in the room. Although outside the scope of this paper, the implications of elderly surveillance systems capable of tracking caregivers is an important case that should be further investigated.
} 
patient's condition" (Chan et al., 2002: 398). As with Algase et al., the suggested implication of this research is that the data generated by monitoring technologies could help caregivers and medical personnel make judgments about when to intervene or take precautions to manage risky behaviors.

The research by Chan et al. and Algase et al. was conducted with elderly residents already diagnosed with dementia who were living in nursing homes or assisted living facilities. Here, data obtained from surveillance systems were verified with the observations of caregiving staff. In the study by Chan et al., the caregiving staff were already monitoring and recording the movements of dementia patients (although no information was given about other responsibilities or interactions that caregivers have with residents). What about the elderly who live alone? Who is monitoring and evaluating their behaviors for pathologies? How do we know that they are safe or that age-related diseases have not compromised their health and wellbeing? Given the threat of wandering, this is where the greatest concern-from the perspective of healthcare professionals, families, and advocacy organizations-lies: with older Americans living alone in their respective communities.

In fact most elderly people with dementia do live at home, and with the increasing emphasis on aging in place, monitoring technologies are being tested for their ability to detect pathological behavioral patterns and thus anticipate certain types of dementia. Building on the assumption that particular patterns of ambulation and activity level are indicative of dementia, a team of medical researchers in Japan conducted a study on the movement patterns of elderly residents living alone-none of whom had been diagnosed with dementia. Citing "the burgeoning cost of medical and nursing care, shortage of nursing care facilities, and increasing number of solitary deaths," this 2005 study addresses the need for early detection within a healthcare system that lacks resources to effectively manage elderly dementia (Suzuki et al., 2007: 41). The study's strategy is to build on the promise and increasing prevalence of commercial surveillance systems being used to monitor the wellbeing of the elderly in Japan and other postindustrial societies. If spatial-temporal movement patterns signify changes in cognitive impairment (as the previous studies allude to) and home security systems are already being positioned to monitor the activities of elderly people opting to (or forced to) age in place, the question becomes whether these systems could also be used to detect the onset of dementia. In the study by Suzuki et al., in-house movements were monitored for a period of three months using passive infrared sensors positioned around the residence-similar to the set up in the study by Chan et al., but covering a much larger area. When the sensors were activated within the radial area, both place and time were recorded on a wireless receiver unit located in the residence. Once daily this information was transmitted to a data center (Suzuki et al., 2007: 41). After the study, elderly participants were evaluated for cognitive impairments using medical history, physical examinations, and neuropsychological tests - the same clinical criteria used to diagnose all cases of dementia. The study found significant correlation between cognitive function, sleep patterns, and number of outings: greater impairment corresponded to fewer outings and shorter sleep cycles (Suzuki et al., 2007: 43). This led researchers to conclude that trends towards "inactivity" and sleep problems were good indicators for the early detection of dementia. As an example of the ways in which surveillance technologies participate in identifying and categorizing disease taxonomy, the study by Suzuki et al. contributes to the biomedicalization of aging. 
These monitoring systems are also indicative of the privatized, individualizing, consumerist healthcare trends that define the aging enterprise. Research by Suzuki et al. in particular was driven by the need to find a low cost and efficient early detection method for elderly populations who are increasingly living alone.

Body sensors may be less desirable than discrete systems embedded within the built environment. In the study by Algase et al., for example, the greatest loss of data resulted from problems with the patient wearing the device (or not wearing the device) (2003: 90). For the elderly aging in place, monitoring devices may get in the way of daily activities, result in discomfort, or might just be one extra thing to keep track of. Given the potential for loss of data and inconvenience to users, it may be advantageous to design systems so that elderly people do not have direct contact with monitoring technologies at all. Along these lines, a U.K. study of smart home design for elderly people with dementia did not even include elderly residents as participants ("No tenants participated in the study."), preferring to focus on caregivers instead (Martin et al., 2007: 144). Like the previous studies examined, this surveillance system included infrared sensors, but also pressure pads, door contacts, and water and cooker valves all linked to a computer monitored by caregivers:

Currently staff can access activity data on each tenant from the main office, and receive a range of alarm alerts to manage risks. The tenants are not required to actively interact with the technology, which discretely gathers computational data on occupant activity within the apartment environment. This data then generates activity algorithms which subsequently produce reports for staff that correlate to tenant activity. The staff reports are presented via user interfaces to inform the care staff of tenant functioning. (Martin et al., 2007: 144)

These surveillance systems are clearly designed to monitor water use, bathroom frequency, sleep patterns, and outings, to name just a few; caregivers (the intended users) reported that such monitoring is desirable (Martin et al., 2007: 145). In the context of the elder-caregiver relationship, how might the caregiver's judgment of the "data" lead to interventions that infringe on the elder's rights? How is power and control leveraged by scrutinizing and evaluating daily activities against constructed norms?

These surveillance systems for the elderly go further than simply tracking, recording, and transmitting data on the movement of bodies. Beyond helping to diagnose and understand behavioral patterns, these surveillance systems are being deployed to control and manage elderly people with dementia while they age in place. A final example is Kinney, Kart, Murdoch, and Ziemba's study on the Xanboo Smart Home Management System, a security platform with a wide range of uses. This system was tested in participants' homes for a period of 24-weeks and included sensors (for phones, bathtubs, windows, and doors), and cameras set up around the home. The sensor system was able to notify caregivers via phone, text, or email. Users (caregivers, family members, or third party interlocutors) can control the entire system from an Internet site, which also has the capacity to save and play back video clips or images (Kinney et al., 2003: 306). Kinney's research developed around caregiver focus groups; participants discussed their greatest challenges as well as their willingness to use technologies for managing care 
responsibilities. Safety was a significant concern: wandering, hiding, and accidents in the kitchen and bathroom were identified as common dementia-care experiences. At the time of the study, many focus group participants were already using intercoms, alarms, and extra locks on exits, and they expressed interest in using monitoring technologies such as cameras to help with supervision. In a thought exercise, group members came up with the idea of wearable cameras:

Participants in two of the groups expressed excitement about a "little necklace-type thing that had a little camera in it" that the individual with dementia would wear at all times, permitting the caregiver to view what is happening from their relative's perspective. Should the individual wander away from home, the camera would transmit an image (ostensibly, to be viewed remotely at a computer monitor) to the caregiver, who would then be able to see where the individual with dementia was wandering. (Kinney et al., 2003: 303)

Decisions may be made on the behalf of elderly people or in their best interest based on somatic or ICT data. If each and every movement is being tracked, recorded and evaluated, will this result in reactions that restrict the activities of elderly people? If monitoring systems are installed in homes and data show that ambulation is random, lapping or pacing, thus indicating increased risk of wandering, will elders then be restricted from leaving their homes (Silverstein et al., 2002)? Power and unequal social relations will undoubtedly infuse such situations - particularly when an elder is dependent upon family or social services and costs of aging in place are significantly less than institutional facilities.

Monitoring systems that track and record movement may be able to indicate disease progression based on behavioral changes; surveillance systems that translate the movements of elderly people with dementia into data not only identify and evaluate risky behavior, but also work to normalize what is acceptable. These cognitive and behavioral norms have been established by experts, medical professionals and caregivers who often have more social power than the elderly in their care,

The community long-term care "system" is more than a system for distributing services; it is a system of social relationships that reflects and bolsters the power inequities between experts and lay persons. This system of care may be deleterious, especially where the emphasis is on social management or control of older persons rather than on opportunities for participation, rehabilitation, and self-determination. (Estes, 1993: 293)

Intervention could be implemented when an elder is suspected of having dementia, or after initial diagnosis. In both cases someone else, a family member, medical practitioner, caregiver, or third party technician may be evaluating and judging an elder's activities against clinical behavioral norms. The emphasis on predicting, diagnosing, and monitoring dementia-prompted by the need to find a cost-efficient yet effective way to care for the elderly aging in place-has led to the increased scrutiny of elderly behaviors and lifestyles. This scrutiny comes primarily from caregivers, medical professionals, and family members who often hold more social power in relation to the elderly. Power 
asymmetries between different age groups are nothing new, but within the political economy of aging, surveillance technologies for the elderly are both reproducing and creating new forms of social control.

\section{Somatic Surveillance}

It is critical to understand elderly monitoring systems as surveillance, as ICTs that construct manageable subjects for increased control in caregiving settings. All of the monitoring systems evaluated are spinoffs from existing biomedical and surveillance systems already in use in other contexts. The products now being employed to understand and manage the behaviors of elderly people with dementia are best characterized as somatic surveillance, "the increasingly invasive technological monitoring of and intervention into bodily functions" (Monahan and Wall, 2007: 154). Monahan and Wall identify three central components of somatic surveillance:

[F]irst, the translation of corporeal information (e.g., heart rate, hormone levels, temperature) into data, usually by means of sensors applied directly to or embedded within the body; second, the communication of those data across networks, effectively situating bodies as "nodes" on larger information networks; and third, the intervention into body functions through various sociotechnical feedback mechanisms. (2007: 154-155)

Surveillance systems for the elderly use sensor technologies to monitor a person's movements-either positioned within the living area or on the body. Mobility is recorded within specific temporal and spatial dimensions, producing data that can be evaluated against existing movement typologies. In nursing homes and assisted living facilities, movement, activity, and access restriction are the most likely care responses because these are some of the only strategies available to dementia caregivers (Silverstein et al., 2002; Kinney et al., 2003; Alzheimer's Disease Education and Referral Center, 2006). Monitoring systems and the data they generate are attractive because they provide a means to track and control dementia without the immediate presence of caregivers. This reinforces broader trends in the political economy of aging-cutting costs through technologies that are intended to reduce labor. If dementia is framed as a social policy time bomb, and current responses by law enforcement and other state agents reflect gaps or at least problematic trends in elderly care, then surveillance appears to offer an attractive solution to a difficult situation. The question is whether intervention via surveillance provides the best possible solution and to what extent this technological fix allows us to brush past the institutional, relational, and ideological forces that underpin the dilemmas of dementia care.

Writing about the state's surveillance of welfare recipients, Virginia Eubanks has argued that data collected and coded using information technology renders contextual information invisible - the daily experiences, motivations, barriers, and emotions of those under surveillance (2006: 91). None of the monitoring systems reviewed in this article incorporate contextual information beyond temporal and spatial data nodes. These technologies do not collect and code information regarding the purpose of movement, nor 
corresponding thoughts and emotions of elderly people under surveillance. In cases where behavioral changes detected by monitoring systems lead to a diagnosis or intervention, will contextual information also be used to judge and make decisions about patient care? How would contextual information be weighed in relation to data generated by ICTs, especially when the patient suffers from cognitive impairment and may not be considered a reliable source of information? Elderly people with dementia are not, after all, the users of monitoring technologies, but rather its target. In some cases, those with dementia may not be aware that they are under surveillance-such as in the case of discrete infrared sensors (Martin et al., 2007:144). None of the above studies describe how somatic data will be used in decision-making processes that intervene in the lives of those with dementia; more commonly, monitoring technologies function as a tool for care management, where the person disappears and their body is coded as a data node (Lyon, 2003; Monahan and Wall, 2007). Eubanks' argument is that IT helps to construct "manageable subjects for governance regimes" (2006: 91). What is important in the context of the social service system are the ways in which surveillance technologies reproduce structural inequalities and power asymmetries. Following along these lines, monitoring technologies similarly construct manageable subjects for healthcare regimes.

Examining the use of RFIDs in hospitals, Jill Fisher underscores the implications of labeling tracking technologies as "indoor positioning systems," a move that depoliticizes both the technologies and their contexts of use. Fisher's argument is that indoor positioning systems are "predisposed to disciplinary and social control uses" even if this is not the intended purpose of such technologies; there are always unintended consequences, and surveillance systems influence management practices and the work experiences of nursing staff (Fisher, 2006: 87). Importantly, indoor positioning systems are employed to help manage "workflow" in hospitals; this is done at the level of individual action instead of at the broader organizational level. In the case of elderly people with dementia, monitoring systems are explicitly about social control-motion sensors are used to track, record, evaluate, and respond to dementia behaviors. Like the case of indoor positioning systems, monitoring technologies focus on individual behaviors or the workplace practices of groups, instead of looking at the bigger picture: aging in the US, dementia care, and the political economy. Surveillance theories can assist in exposing some of the social, political, and economic dynamics that may be difficult to see when the focus is on the beneficial uses of monitoring systems. As Joyce and Mamo have pointed out, technologies are "central producers of the meaning of 'normal' aging and the embodied, lived experiences of old age” (2006: 100). Surveillance technologies for the elderly are no different, making it important to think about how these systems will shape dementia care.

\section{Ageism in Place}

Dementia is unique in that cognitive degeneracy far precedes physical debilitation, often leaving a person fully functioning physically but mentally and emotionally impaired to varying degrees. In the US, the dangers posed by dementia are well documented, leading many in the caregiving profession to advocate for extensive precautions and safety mechanisms (Kinney et al., 2003; Silverstein et al., 2002; Chan et al., 2002; Alzheimer's 
Association, 2006). Both the conditions of dementia and the privatization of healthcare have spurred the development of elderly surveillance systems; put bluntly, exercising control over elderly people with dementia seems to be necessary and may be the best way to ensure wellbeing. Faced with the social and economic burdens of an aging population, if monitoring systems advance further understandings of dementia, help caregivers manage their responsibilities, and keep the elderly safe, how concerned should the public be about issues that have always plagued caregiving relations-control, privacy, autonomy, and power asymmetries? My argument is that these issues warrant renewed attention given the political economy of aging in the development and deployment of surveillance technologies for the elderly.

Attention to ageism-oppression and inequalities produced by age relations-is often absent in studies of dementia and caregiving technologies. Calasanti and Slevin map out three dimensions of age relations: that age functions as a social organizing principle that the power and identities of different age groups are constituted through their relations with other age groups, and that age relations intersect with other social hierarchies and power relations (2006: 5). Age relations shape people's perceptions and play a key role in identity construction:

Oppressed people are subject to marginalization (e.g., loss of income and subsequent material deprivation on retirement), violence (e.g., elder abuse), powerlessness, (e.g., inability to influence decisions that affect one's life), exploitation (e.g., children reaping the benefits of the unpaid labor of an elderly woman), and cultural imperialism (e.g., the emphasis on youth and vitality that undermines the positive contributions of older people). (Laws 1995: 113)

Even though surveillance technologies promise freedom and autonomy for the elderly, these goods are based on the system's ability to monitor and secure the body. For older Americans, wellbeing has come to mean physical safety where the greatest threat is posed by the aging body itself. The examples of monitoring systems in institutional facilities, homecare, and law enforcement agencies demonstrate that data generated by surveillance technologies often result in increased monitoring, access or mobility restriction, or further medical interventions - these are the reactions of persons who are caring for or otherwise socially responsible for elderly citizens. Interventions may or may not be necessary; what is important is that judgments and decisions are not made by the elderly themselves, but by those who are responsible for their wellbeing. Furthermore, care responses are conditioned by the biomedicalization and commodification of aging, trends that must be historically situated and analyzed within a sociocultural, economic, and political framework.

Has technology ever produced a clear-cut fix for social, political, and ethical dilemmas? Despite their usefulness in the context of elderly care, RFIDs and monitoring systems must still be understood as technologies of control that are predisposed to reproduce existing inequalities in social relations. By situating surveillance of the elderly within the political economy of aging, it is evident that these technologies both construct and manage a risk population in an increasingly profitable healthcare regime. Researchers, innovators and adopters should be attentive to the ways in which monitoring systems 
reproduce dependencies, contribute to disease taxonomies, redefine the meaning of care, individualize risk, and enable or constrain liberties. Surveillance systems can address the needs of caregivers, the elderly who wish to age in place, and broader social institutions, but current articulations of these systems do not explicitly challenge the ideologies and structural inequalities that disadvantage the elderly in the first place; if anything they reentrench and reinforce the norms, hierarchies, and oppression of ageism by rendering them invisible.

\section{References}

ABC News "Coroner recommends dementia wards be fitted with CCTV" 21 Nov. 2007. http://www.abc.net.au/news/stories/2007/11/21/2097292.htm

Algase, D.L., Beattie, E.R., Leitsch, S. A., Beel-Bates, C.A. (2003) Biomechanical activity devices to index wandering behavior in dementia. American Journal of Alzheimer's Disease and Other Dementias, 18(2), 85-92.

Alzheimer's Association. (2007) Alzheimer's Disease Facts and Figures 2007. Chicago, Il.

Alzheimer's Disease Education and Referral Center. (2006) Home safety for people with Alzheimer's disease. National Institute on Aging, NIH Publication No. 02-5179.

Calasanti, T.M., \& Slevin, K.F. (2006) Age Matters: Realigning feminist thinking. New York: Routledge.

Chan, M., Campo, E., Laval, E., Esteve, D. (2002) Validation of a remote monitoring system for the elderly: Application of mobility measurements. Technology and Health Care, 10, 391-399.

Clarke, A.E., Mamo, L., Fishman, J.R., Shim, J.K., \& Fosket, J.R. (2003) Biomedicalization: Technoscientific transformations of health, illness, and U.S. biomedicine. American Sociological Review, 68(2), 161-194.

Estes, C.L. (ed.) (2001) Social Policy and Aging: A Critical Perspective. Thousand Oaks: Sage Publications.

Estes, C.L. (1993) The aging enterprise revisited. The Gerontologist, 33(3), 292-298.

Estes, C.L. (1979) The Aging Enterprise: A critical examination of social policies and services for the aged. San Francisco: Jossey-Bass Publishers.

Estes, C.L. and Binney, E.A. (1989) The biomedicalization of aging: Dangers and dilemmas. The Gerontologist, 29(5), 587-596.

Eubanks, V. (2006) Technologies of citizenship: Surveillance and political learning in the welfare system. In T. Monahan (ed), Surveillance and Security: Technological Politics and Power in Everyday Life. New York, NY: Routledge, 89-108.

Fisher, J.A. (2006) Indoor positioning and digital management: Emerging surveillance regimes in hospitals. In T. Monahan (ed), Surveillance and Security: Technological Politics and Power in Everyday Life. New York, NY: Routledge, 77-88.

Gray, L.R. (2007) “Devices available for people with dementia.” Herald Tribune, 17 Nov. 2007. 22 Nov. 2007. http://www.heraldtribune.com/article/20071117/NEWS/711170540/1006/SPORTS

Gubrium, J.F. (1986) Oldtimers and Alzheimer's: The descriptive organization of senility. Greenwich, CN: 
JAI Press, Inc.

Harbert, T. (2006) House calls make a comeback. Design News, 11 Dec. 2006.

Joyce, K., Mamo, L. (2006) Graying the cyborg: New directions in feminist analyses of aging, science, and technology. In T.M. Calasanti \& K.F. Slevin (eds), Age Matters: Realigning Feminist Thinking. New York, NY: Routledge, 99-121.

Katz, C. (2006) The state goes home: Local hypervigilance of children and the global retreat from social reproduction. In T. Monahan (ed), Surveillance and Security: Technological Politics and Power in Everyday Life. New York, NY: Routledge, 27-36.

King, N. (2006) The lengthening list of oppressions: Age relations and the feminist study of inequality. In T.M. Calasanti \& K.F. Slevin (eds), Age Matters: Realigning Feminist Thinking. New York, NY: Routledge, 47-74.

Kinney, J.M., Kart, C.S, Murdoch, L.D., \& Ziemba, T.F. (2003) Challenges in caregiving and creative solutions: Using technology to facilitate caring for a relative with dementia. Ageing International, 28(3), 295-314.

Laws, G. (1995) Understanding ageism: Lessons from feminism and postmodernism. The Gerontologist, 35(1), 112-118.

Lyon, D., ed. (2003) Surveillance as Social Sorting: Privacy, Risk, and Digital Discrimination. New York, NY: Routledge.

Martin, S., Nugent, C., Wallace, J., Kernohan, G., McCreight, B., Mulvenna, M. (2007) Using context awareness within the 'Smart home' environment to support social care for adults with dementia. Technology and Disability, 19, 143-152.

Martino-Saltzman, D., Blasch, B.B., Morris, R.D. (1991) Travel behavior in nursing home residents perceived as wanderers and nonwanderers. The Gerontologist, 31(5), 666-672.

Mitchell, M. (2007) “No justification for using Taser on grandma.” Chicago Sun-Times, 6 Nov. 2007.12 Nov. 2007 http://www.suntimes.com/news/mitchell/636574,CST-NWS-mitch06.article

Mitchell, M. (2007) “Cops wouldn’t take no for an answer.” Chicago Sun-Tribune, 7 Nov. 2007. 12 Nov. 2007 http://www.suntimes.com/news/mitchell/638188,CST-NWS-mitch07.article

Monahan, T. \& Wall, T. (2007) Somatic surveillance: Corporeal control through information networks. Surveillance \& Society, 4(3), 154-173.

Monahan, T. (ed) (2006) Surveillance and Security: Technological politics and power in everyday life. New York: Routledge.

Project Lifesaver. (2007) Project Lifesaver [website] 22 Nov. 2007 http://www.projectlifesaver.org/site/

Orpwood, R., Sixsmith, A., Torrington, J., Chadd, J., Gibson, G, \& Chalfont, G. (2007) Designing technology to support quality of life of people with dementia. Technology and Disability, 19(2/3), 103-112.

Silverstein, N.M., Flaherty, G., and Terri Salmons Tobin. (2002) Dementia and Wandering Behavior: Concern for the Lost Elder. New York: Springer Publishing Company.

Sloane, P.D., Zimmerman, S., Suchindran, C., Reed, P., Wang, P., Boustani, M., Sudha, S. (2002) The public health impact of alzheimer's disease, 2000-2050: Potential implications of treatment advances. Annual Review of Public Health, 23, 213-231. 
Suzuki, T., Murase, S., Tanaka, T., \& Okazawa, T. (2006) New approach for the early detection of dementia by recording in-house activities. Telemedicine and e-Health, 13(1), 41-44.

Twine, F. (1994) Citizenship and Social Rights: The interdependence of self and society. Thousand Oaks, CA: Sage Publications. 